\title{
Monodisperse Bismuth-Halide Double Perovskite Nanocrystals Confined in Mesoporous Silica Templates
}

Yue-Qiao Hu, * Li-Juan Fan, Hong-Yan Hui, Hong-Qiang Wen, De-Suo Yang, * Guo-Dong Feng*

Key Laboratory of Advanced Molecular Engineering Materials, College of Chemistry and Chemical Engineering, Baoji University of Arts and Sciences, Baoji 721013, China. No. 1, Hi-Tech Avenue, Baoji 


\section{Synthesis of mesoporous silica templates}

KIT-6 A mixture of $2 \mathrm{~g}$ P123 (Aldrich, $\mathrm{EO}_{20} \mathrm{PO}_{70} \mathrm{EO}_{20}, \mathrm{Ma}=5800$ ), $5 \mathrm{ml}(12 \mathrm{M}) \mathrm{HCl}$ and $108.5 \mathrm{ml}$ water was stirred well in a beaker at room temperature $\left(35^{\circ} \mathrm{C}\right)$. Then, $3.75 \mathrm{ml} \mathrm{N}$-butyl alcohol was added and continuous stirred for $1 \mathrm{~h}$ before adding 6.9 $\mathrm{ml}$ TEOS, and the second mixture was stirred for $24 \mathrm{~h}$ at $35^{\circ} \mathrm{C}$ before transferring into a Teflon bottle and heating at $100{ }^{\circ} \mathrm{C}$ for $24 \mathrm{~h}$ in the oven. The final product was got by filtering, washing with water, drying at room temperature and calcining in muffle furnace at $550^{\circ} \mathrm{C}$ for $6 \mathrm{~h}$.

SBA-15 4.0 g P123 was dissolved by stirring vigorously in a solution of $126 \mathrm{~mL}$ deionized water and $24 \mathrm{ml}(2 \mathrm{M}) \mathrm{HCl}$, then $9.2 \mathrm{ml}$ TEOS wad added into the solution. After stirring for $24 \mathrm{~h}$ at $40{ }^{\circ} \mathrm{C}$, the mixture was transferred into a Teflon bottle and heated at $100{ }^{\circ} \mathrm{C}$ for $24 \mathrm{~h}$. After the reaction, the product was filtered, washed with water and dried at $60{ }^{\circ} \mathrm{C}$, and then calcined in muffle furnace at $550{ }^{\circ} \mathrm{C}$

MCM-41 2 g CTAB was dissolved in a solution of $100 \mathrm{ml}$ water and $8.8 \mathrm{ml} 45 \%$ $\mathrm{NH}_{3} \cdot \mathrm{H}_{2} \mathrm{O}$, then $8.3 \mathrm{ml}$ TEOS was injected into the mixture with an injection pump for $1 \mathrm{~h}$. The solution was stirred for $24 \mathrm{~h}$ at room temperature, the gel solution was transferred into a Teflon bottle and crystallized at $100{ }^{\circ} \mathrm{C}$ for $24 \mathrm{~h}$. Finally, the product was obtained through filtering, washing with water, drying at $60{ }^{\circ} \mathrm{C}$ and calcining in muffle furnace at $550{ }^{\circ} \mathrm{C}$ for $6 \mathrm{~h}$.

The phase and purity of above three templets were proved by SAXS data in Figure S4-6, their BET surface and pore size were carried out by physical adsorption/desorption experiments in Figure S7-12. 


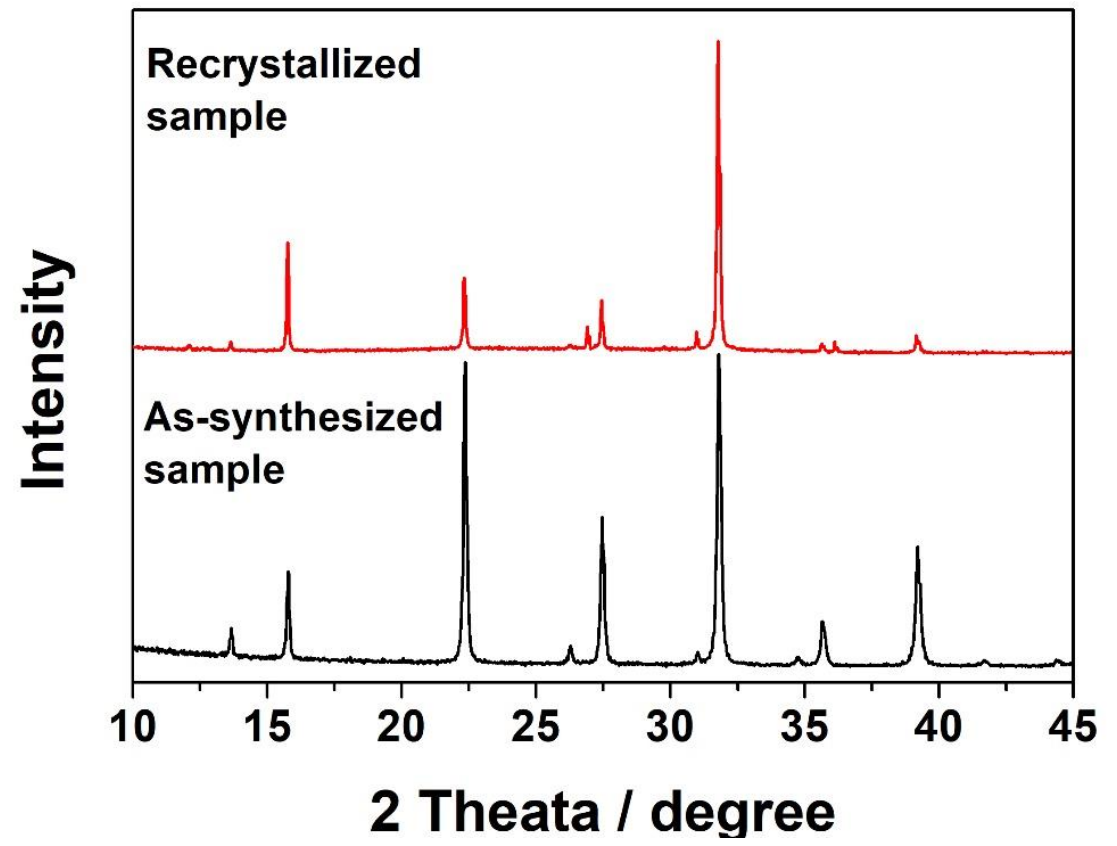

Figure S1. PXRD of the as-synthesized and recrystallized samples of $\mathbf{1}$. 


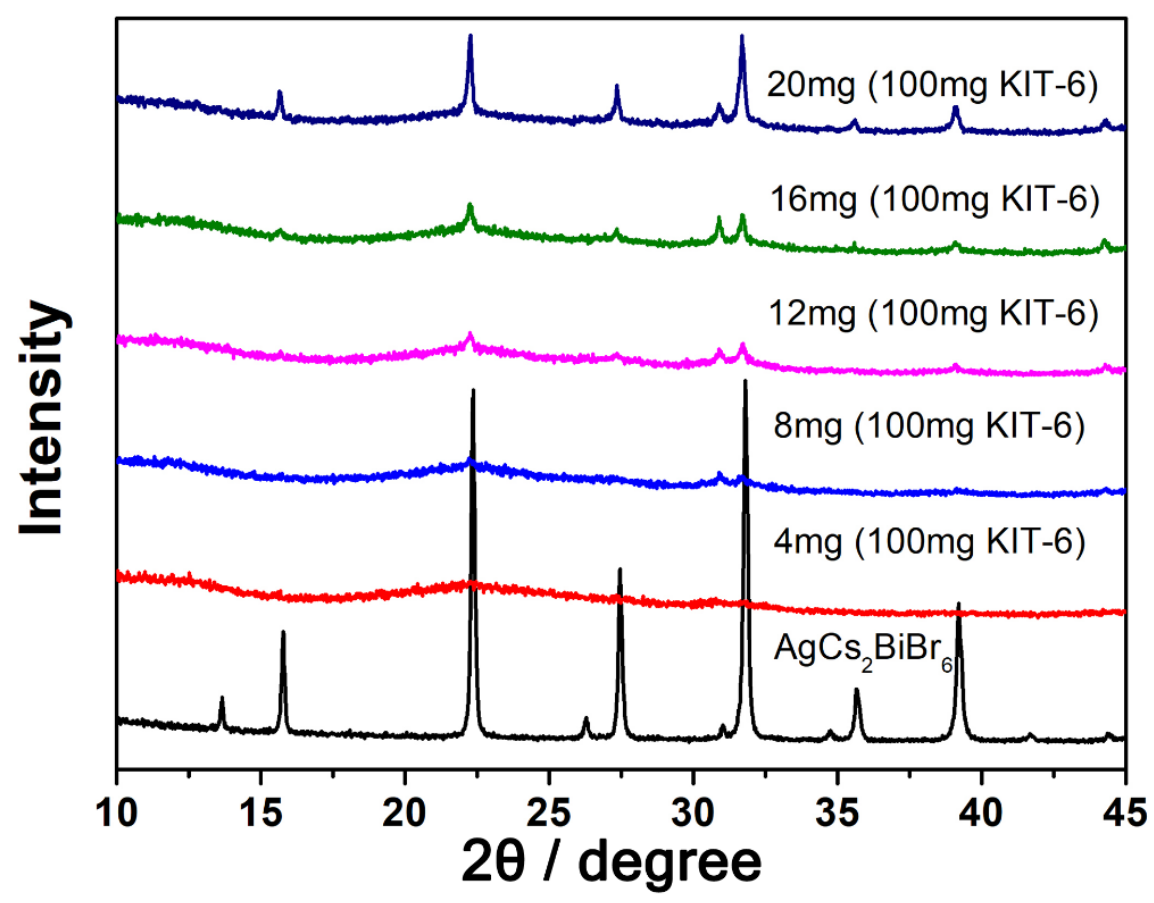

Figure S2. PXRD of $1 @$ KIT-6 with different loading amount.

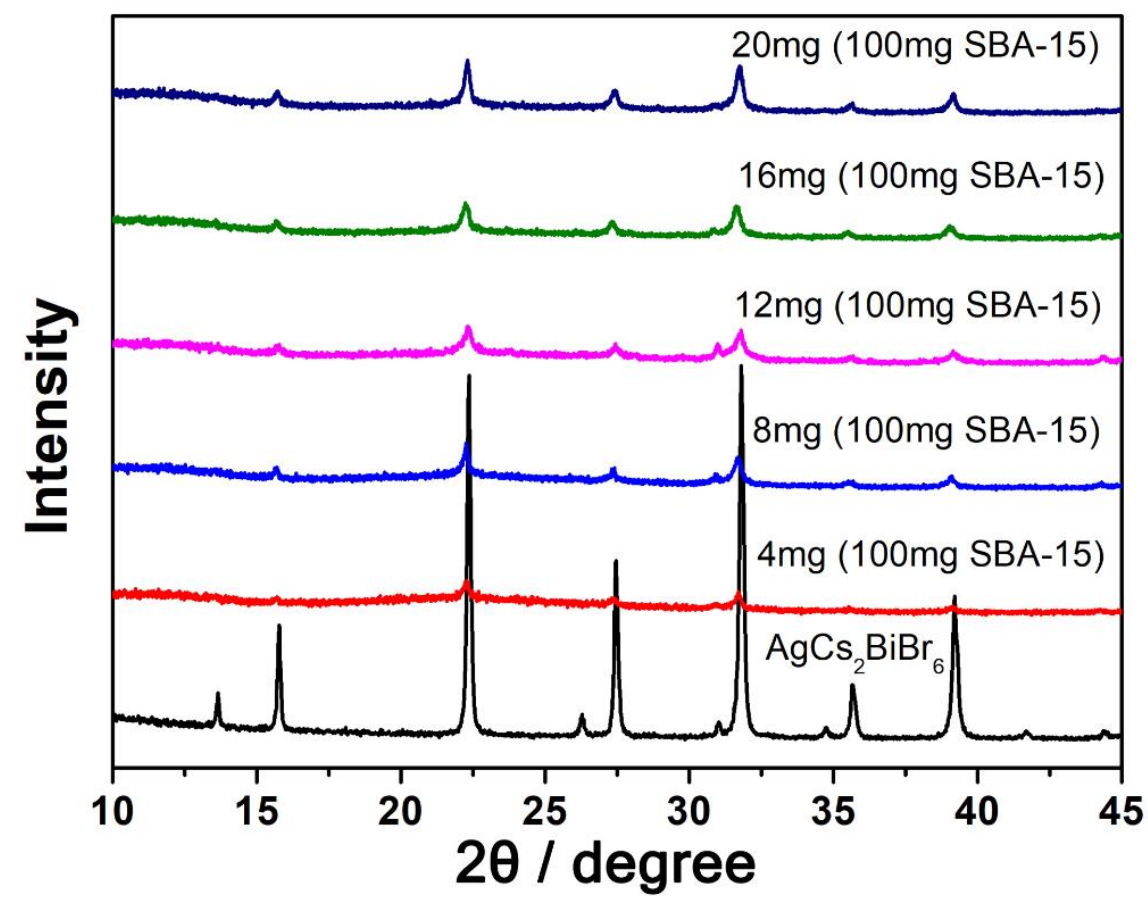

Figure S3. PXRD of $1 @$ SBA-15 with different loading amount. 


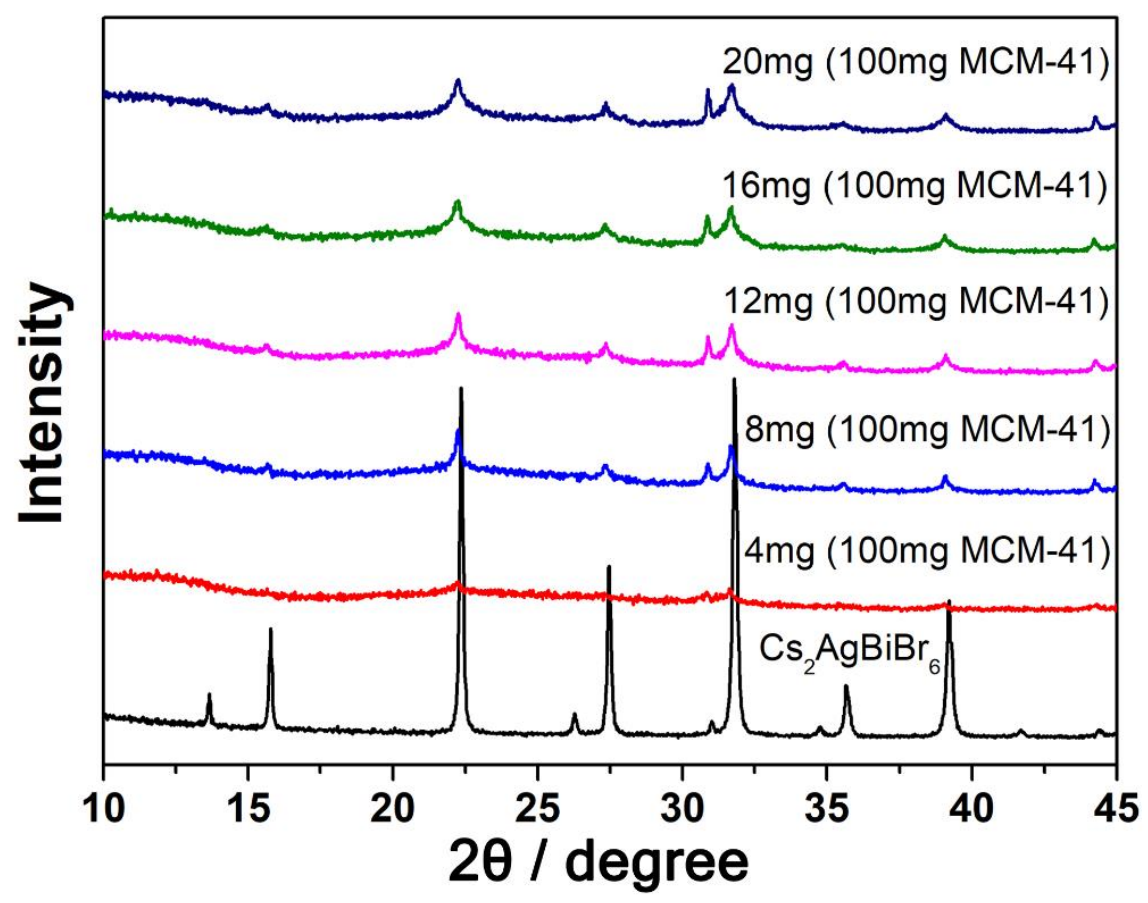

Figure S4. PXRD of $1 @$ MCM-41 with different loading amount.

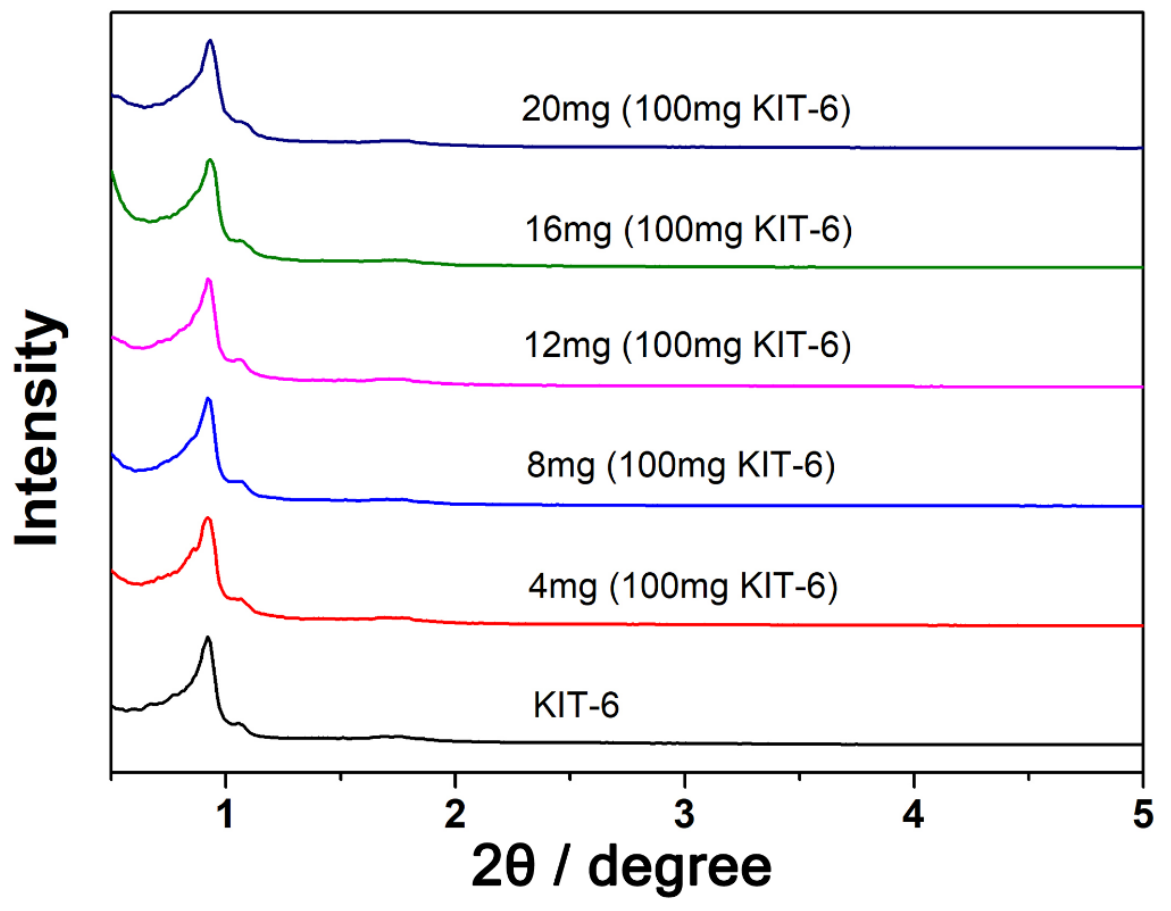

Figure S5. SAXS of $1 @$ KIT-6 with different loading amount. 


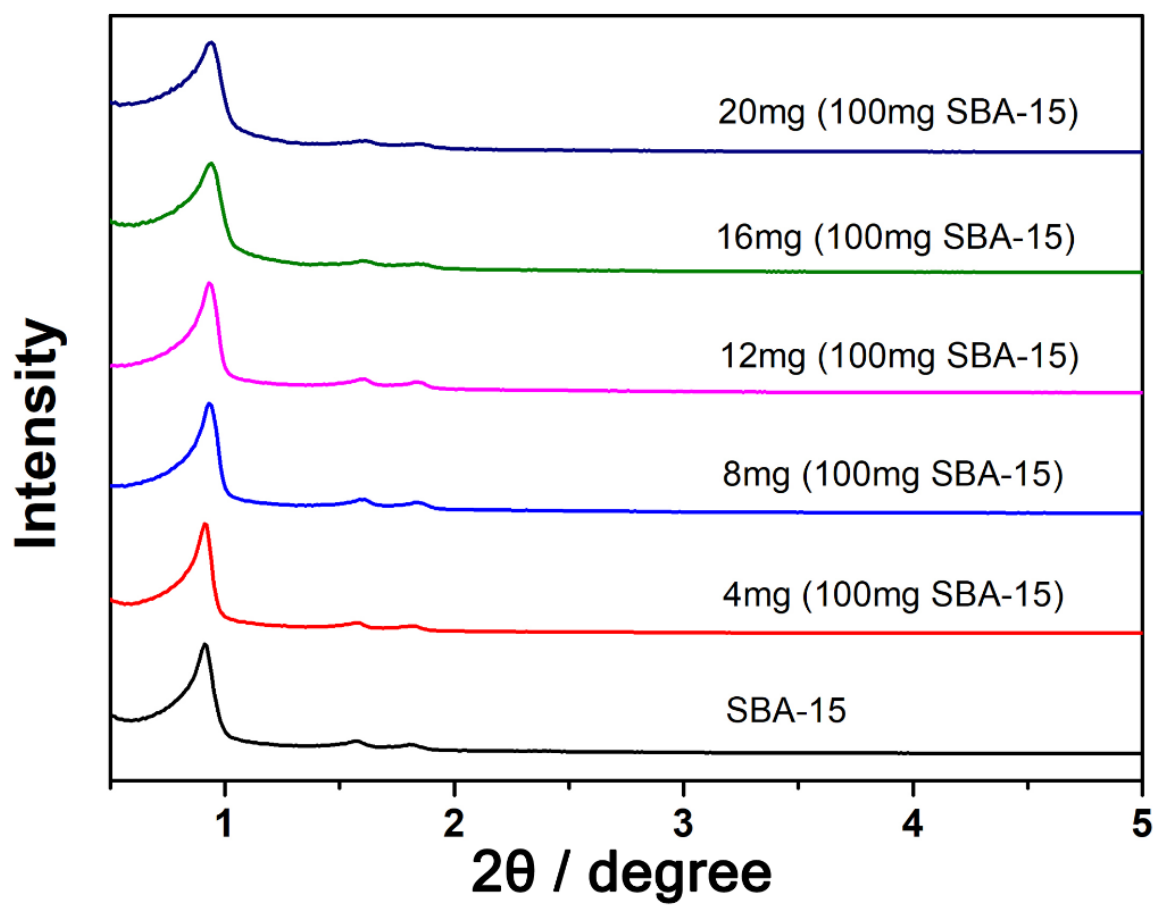

Figure S6. SAXS of $1 @$ SBA-15 with different loading amount.

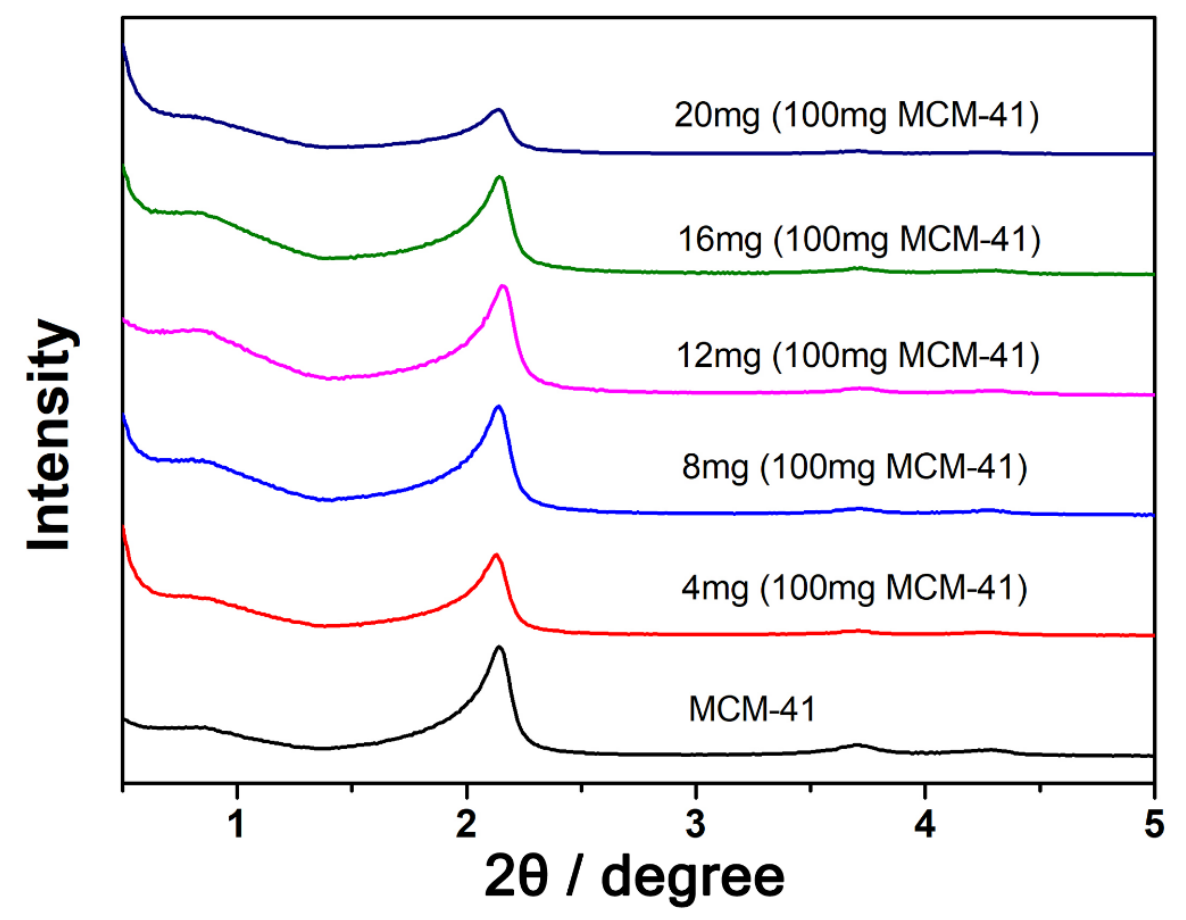

Figure S7. SAXS of $1 @$ MCM-41 with different loading amount. 


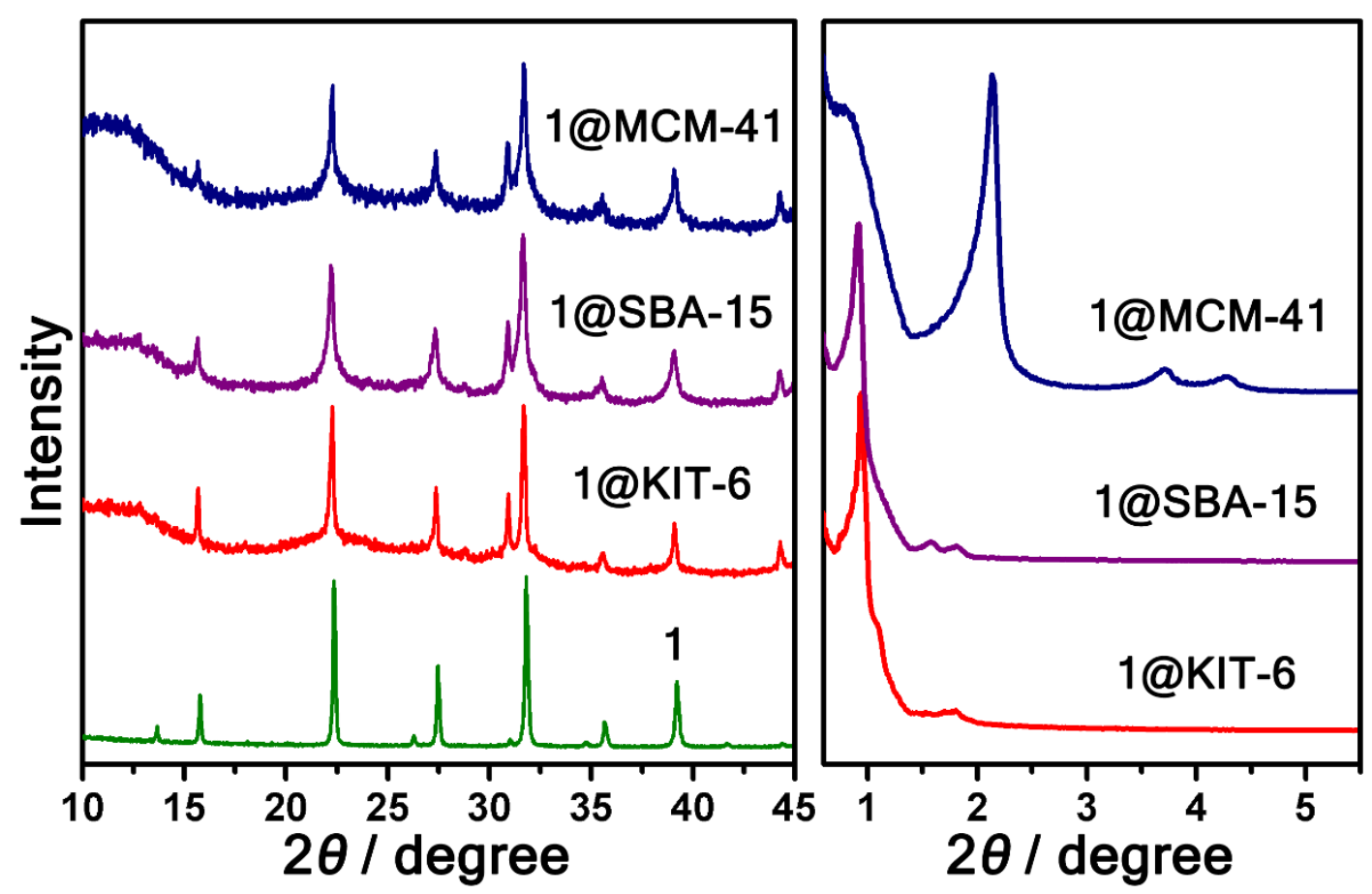

Figure S8. Stability of $1 @$ KIT-6, $1 @$ SBA-15, $1 @$ MCM-41. The newly prepared samples were kept in air with relative humidity of $55 \%$ for 180 days, and the PXRD patterns of $1 @$ KIT-6, $1 @$ SBA-15, $1 @$ MCM-41 after moisture showed no evidence of material decomposition, which proves the high stability of the samples. 


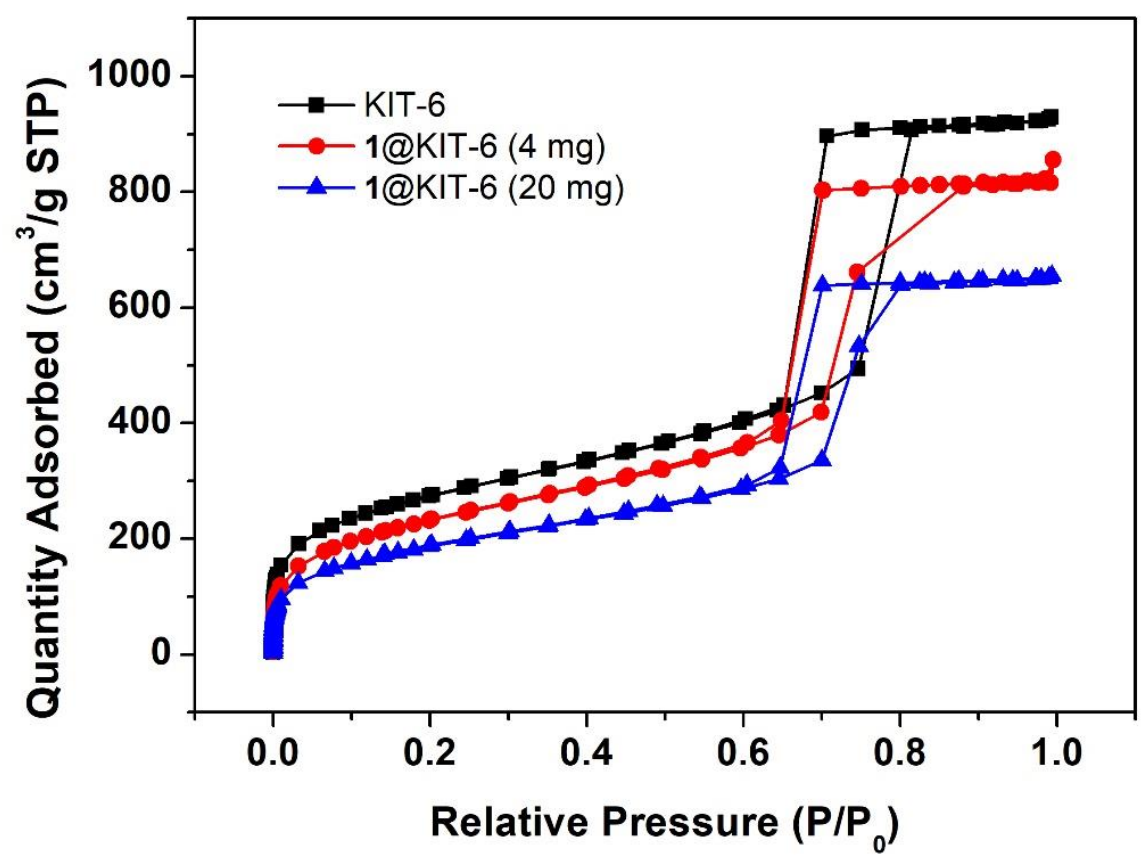

Figure S9. $\mathrm{N}_{2}$ adsorption/desorption data of KIT-6 and 1@KIT-6 with different loading amount.

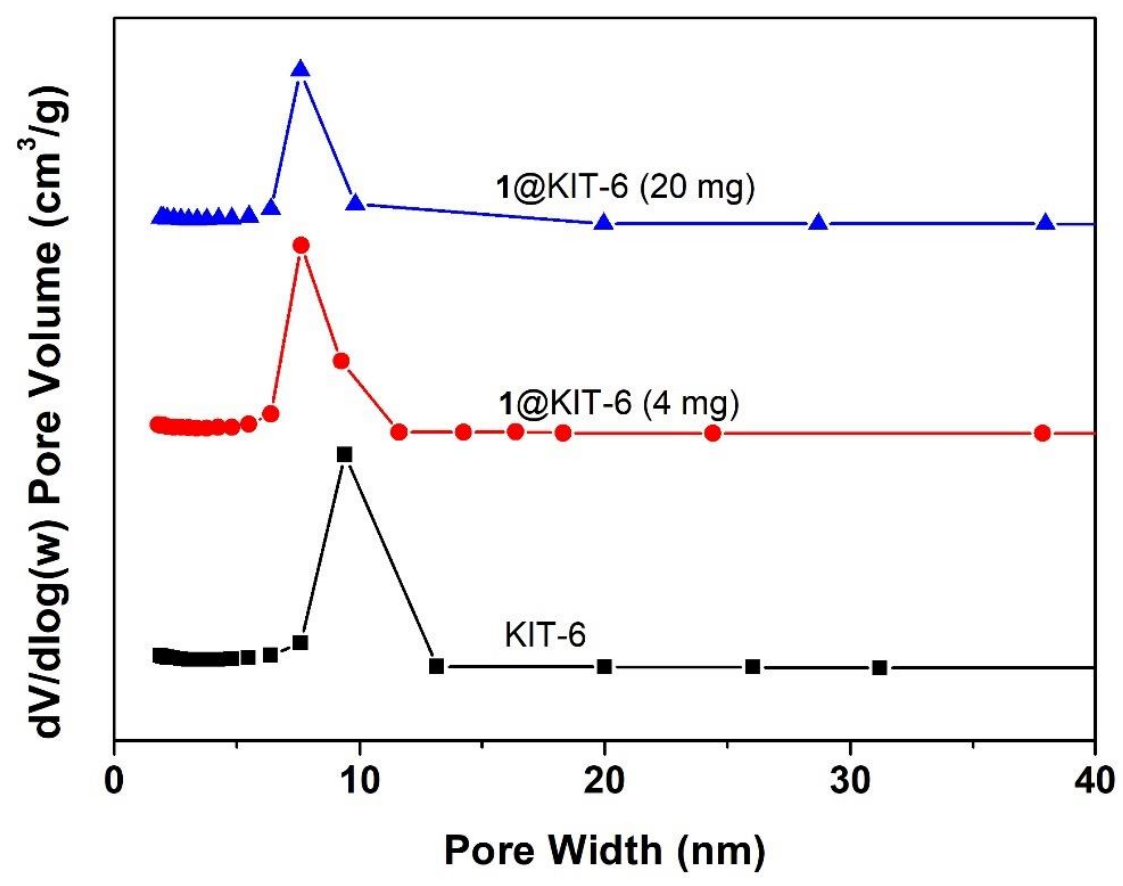

Figure S10. Pore size distribution of KIT-6 and $1 @$ KIT-6 with different loading amount. 




Figure S11. $\mathrm{N}_{2}$ adsorption/desorption data of SBA-15 and 1@SBA-15 with different loading amount.

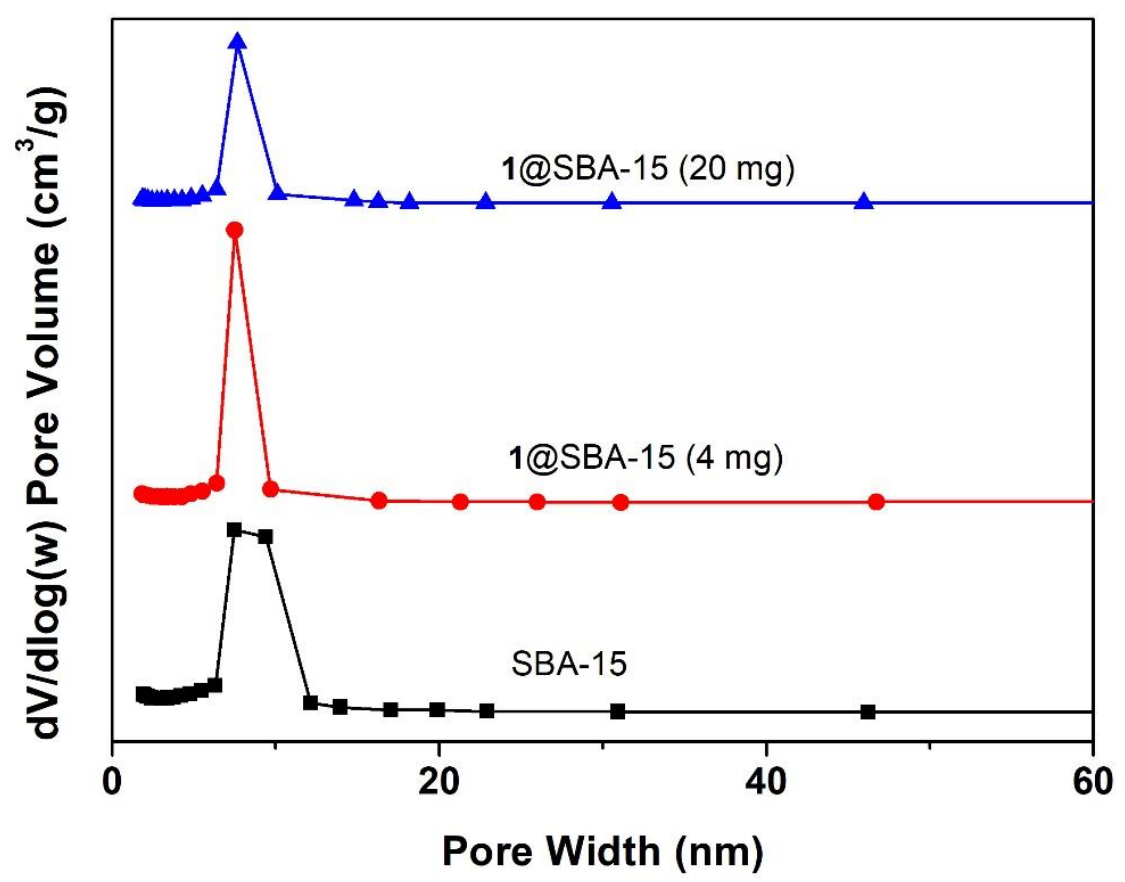

Figure S12. Pore size distribution of SBA-15 and 1@SBA-15 with different loading amount. 


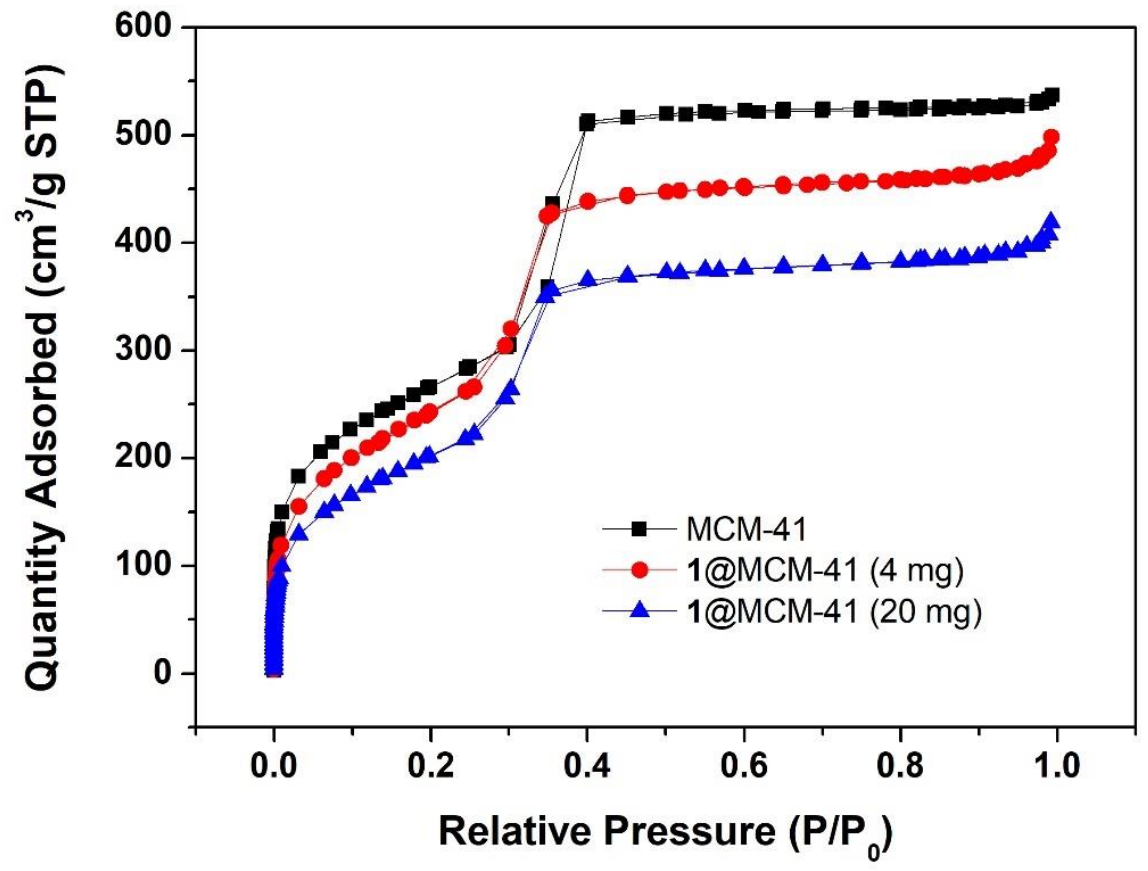

Figure S13. $\mathrm{N}_{2}$ adsorption/desorption data of MCM-41 and 1@MCM-41 with different loading amount.

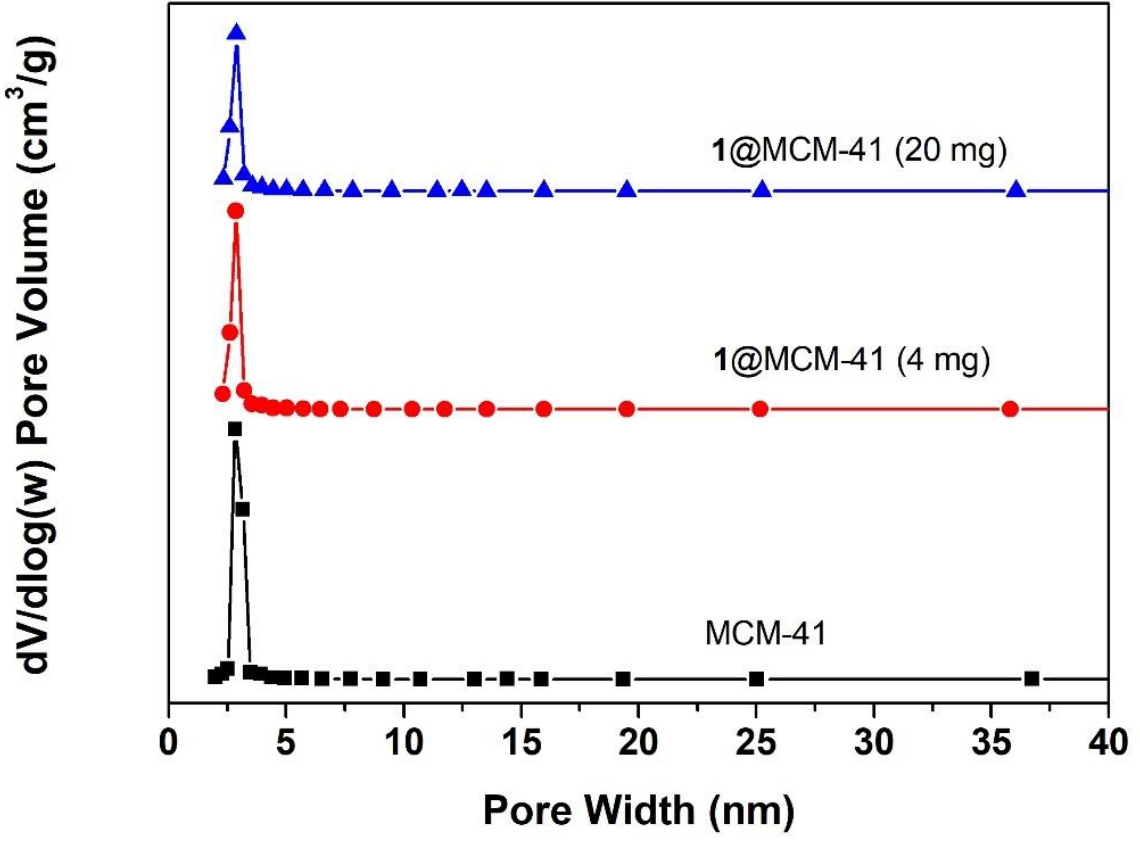

Figure S14. Pore size distribution of MCM-41 and 1@MCM-41 with different loading amount. 
Table S1. Comparison of specific surface area and pore size of mesoporous silicon before and after loading samples.

\begin{tabular}{cccc}
\hline Sample & $\begin{array}{c}\text { BET surface } \\
\left(\mathrm{m}^{2} / \mathrm{g}\right)\end{array}$ & $\begin{array}{c}\text { Pore volume } \\
\left(\mathrm{cm}^{3} / \mathrm{g}\right)\end{array}$ & $\begin{array}{c}\text { Pore size } \\
(\mathrm{nm})\end{array}$ \\
\hline KIT-6 & 971 & 1.44 & 5.92 \\
1 @ KIT-6 (4 mg) & 853 & 1.33 & 6.02 \\
1@ KIT-6 (20 mg) & 675 & 1.01 & 6.12 \\
SBA-15 & 857 & 1.19 & 5.66 \\
1 @SBA-15 (4 mg) & 530 & 1.02 & 5.72 \\
1@SBA-15 (20 mg) & 425 & 0.81 & 5.81 \\
MCM-41 & 954 & 0.83 & 2.99 \\
1@MCM-41 (4 mg) & 852 & 0.76 & 3.02 \\
1@MCM-41 (20 mg) & 753 & 0.72 & 3.07 \\
\hline
\end{tabular}




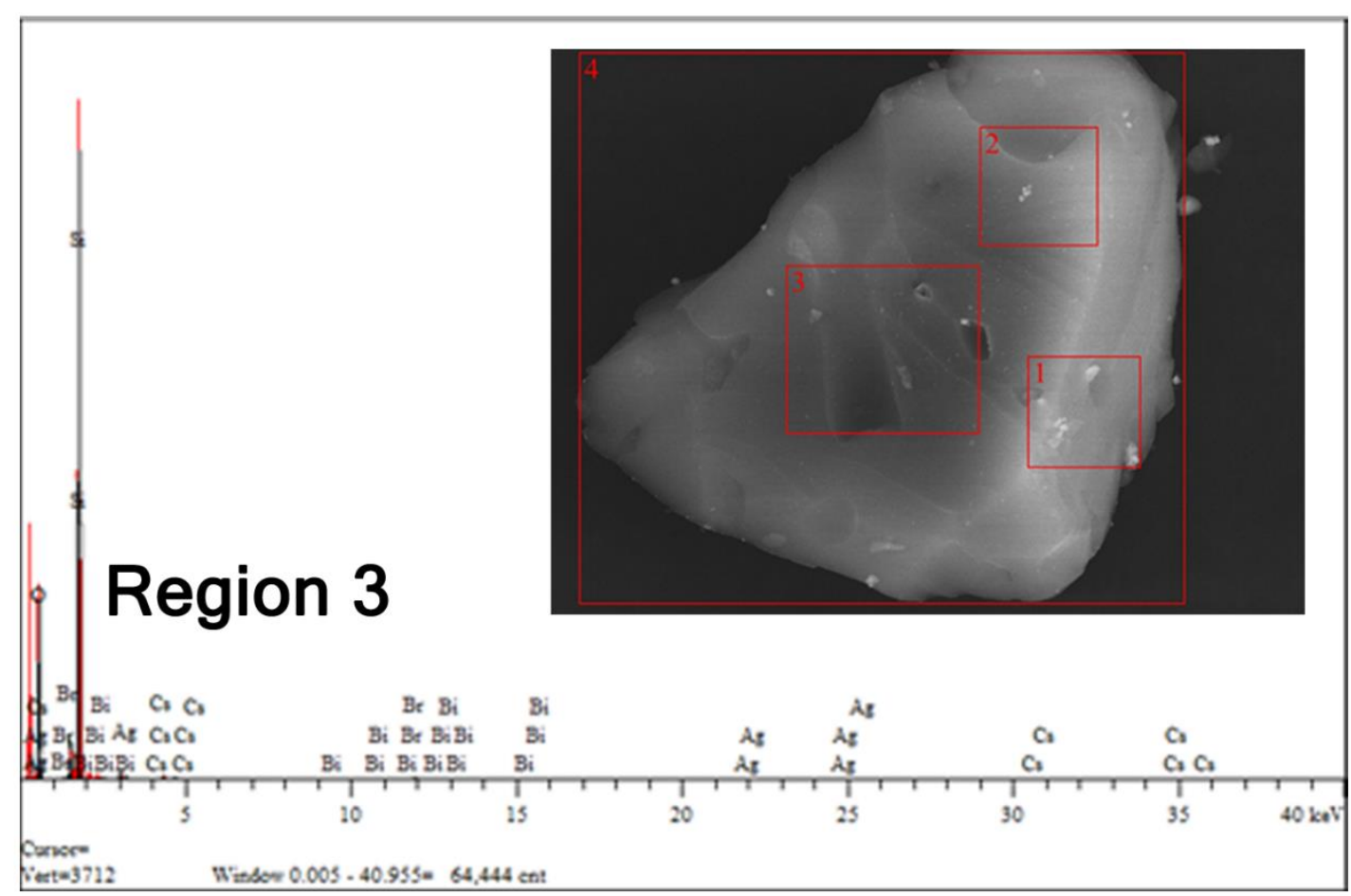

Figure S15. EDX image of $1 @$ KIT-6 (20 mg 1 in 100 mg KIT-6).

Table S2. EDX data of 1 @ KIT-6 (20 mg 1 in 100 mg KIT-6).

\begin{tabular}{ccccc}
\hline Element & $\begin{array}{c}\text { Region 1 } \\
\text { Atomic } \%\end{array}$ & $\begin{array}{c}\text { Region 2 } \\
\text { Atomic \% }\end{array}$ & $\begin{array}{c}\text { Region 3 } \\
\text { Atomic \% }\end{array}$ & $\begin{array}{c}\text { Region 4 } \\
\text { Atomic \% }\end{array}$ \\
\hline $\mathrm{Cs}$ & 0.592 & 0.536 & 0.596 & 0.494 \\
$\mathrm{Ag}$ & 0.255 & 0.252 & 0.304 & 0.249 \\
$\mathrm{Bi}$ & 0.269 & 0.265 & 0.315 & 0.238 \\
\hline
\end{tabular}




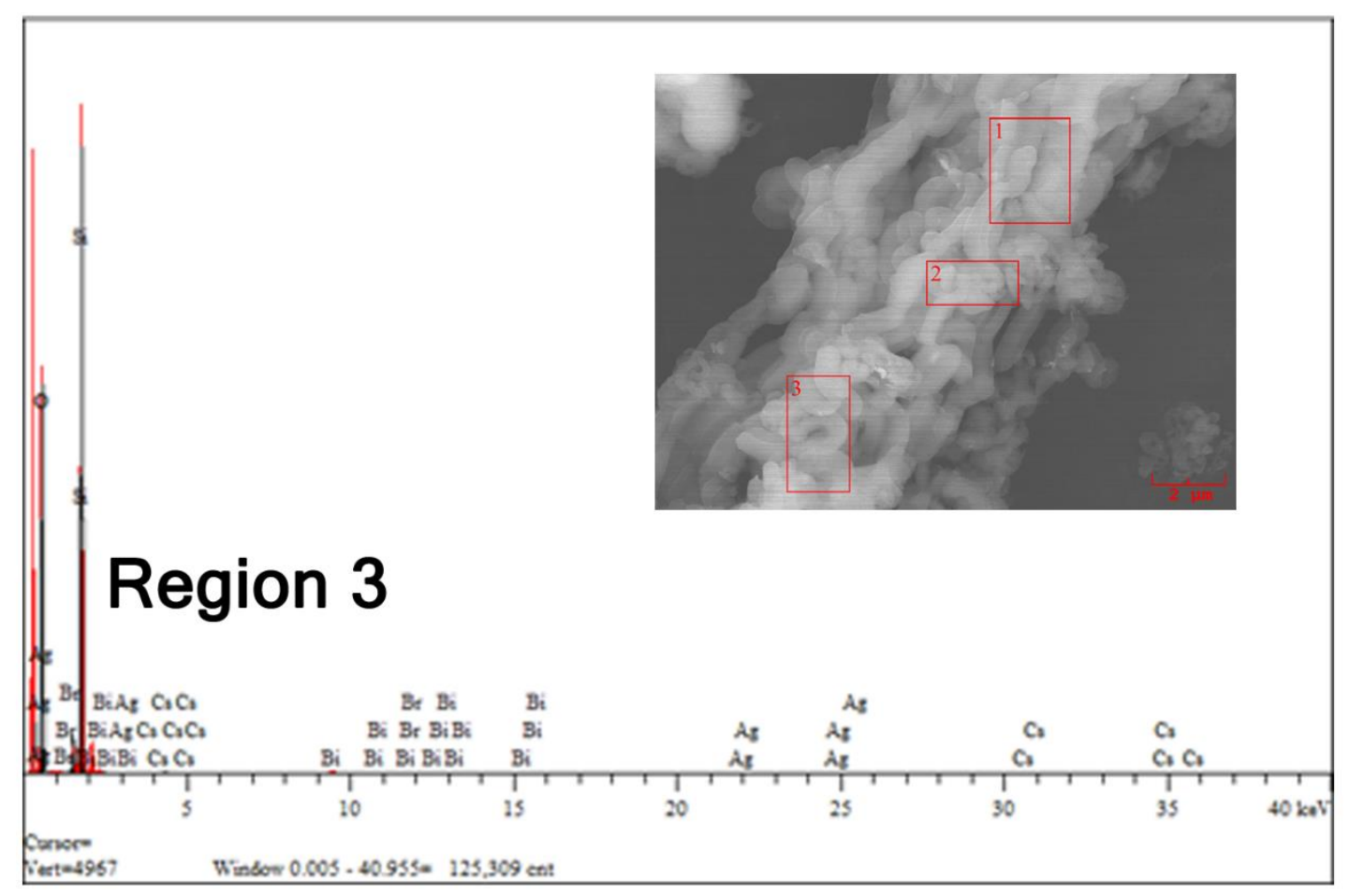

Figure S16. EDX image of $1 @$ SBA-15 (20 mg 1 in 100 mg SBA-15).

Table S3. EDX data of $1 @$ SBA-15 (20 mg 1 in 100 mg SBA-15).

\begin{tabular}{cccc}
\hline Element & $\begin{array}{c}\text { Region } 1 \\
\text { Atomic } \%\end{array}$ & $\begin{array}{c}\text { Region 2 } \\
\text { Atomic \% }\end{array}$ & $\begin{array}{c}\text { Region 3 } \\
\text { Atomic \% }\end{array}$ \\
\hline $\mathrm{Cs}$ & 0.437 & 0.473 & 0.573 \\
$\mathrm{Ag}$ & 0.211 & 0.244 & 0.273 \\
$\mathrm{Bi}$ & 0.224 & 0.273 & 0.296 \\
\hline
\end{tabular}






Figure S17. EDX image of $1 @$ MCM-41 (20 mg 1 in 100 mg MCM-41).

Table S4. EDX data of $1 @$ MCM-41 (20 mg 1 in 100 mg MCM-41).

\begin{tabular}{ccccc}
\hline Element & $\begin{array}{c}\text { Region } 1 \\
\text { Atomic } \%\end{array}$ & $\begin{array}{c}\text { Region 2 } \\
\text { Atomic } \%\end{array}$ & $\begin{array}{c}\text { Region 3 } \\
\text { Atomic \% }\end{array}$ & $\begin{array}{c}\text { Region 4 } \\
\text { Atomic \% }\end{array}$ \\
\hline $\mathrm{Cs}$ & 0.195 & 0.174 & 0.213 & 0.184 \\
$\mathrm{Ag}$ & 0.111 & 0.089 & 0.104 & 0.106 \\
$\mathrm{Bi}$ & 0.098 & 0.096 & 0.105 & 0.090 \\
\hline
\end{tabular}



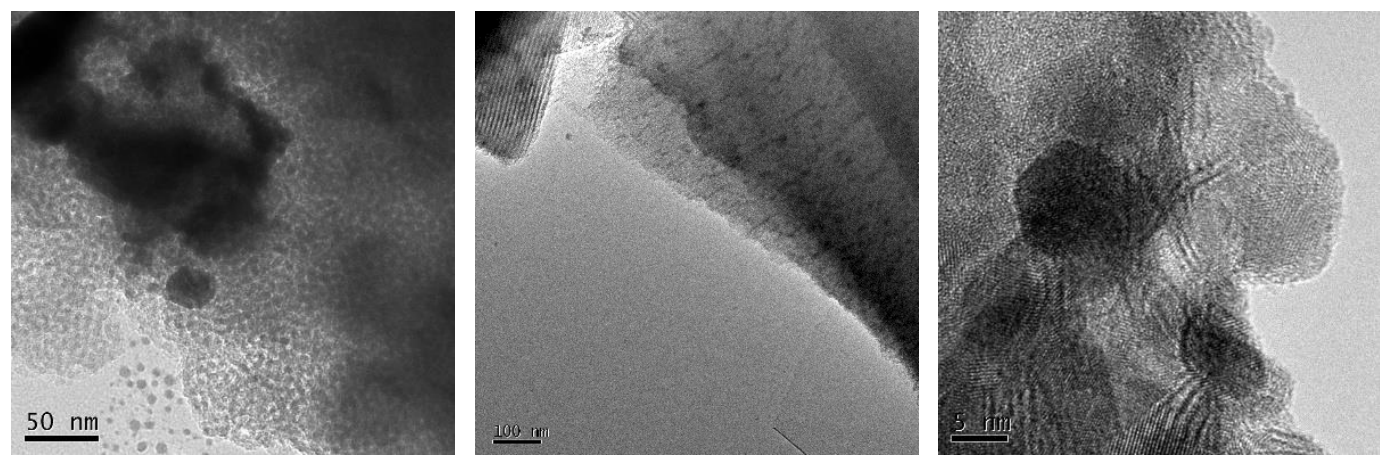

Figure S18. TEM images of 1@KIT-6 (left), 1@SBA-15 (middle) and 1@MCM-41 (right). In order to prove the morphology of our samples, we extend the time when the electron beam hit the samples. As shown in Figure $\mathrm{S} 18$ left, $\mathrm{SiO}_{2}$ on KIT-6 will be destroyed or even "dissolved" by long-term electron beam bombardment. However, complex 1, which is composed of heavy metal ions and halogens, can remain crystalline even after being bombarded by electron beams for a long time. We can see from the figure that there is a clear gap between the nanocrystals of $\mathbf{1}$, that is, the destroyed $\mathrm{SiO}_{2}$. It can be inferred that the nanocrystals of $\mathbf{1}$ are monodisperse nanocrystals separated by $\mathrm{SiO}_{2}$. At the same time, because $\mathrm{SiO}_{2}$ is dissolved at the edge of the material, the nanocrystals will detach from the channel, which is just proof of that. For 1@SBA-15 (Figure S18 middle), we can see in the picture that there are indeed two kinds of nanocrystals: 0D (shorter) and 1D (longer) in the channel of SBA-15. These nanocrystals are separated by $\mathrm{SiO}_{2}$ and are also monodisperse nanocrystals. For $1 @$ MCM-41 (Figure S18 right), we can also see that one-dimensional nanocrystals are separated by $\mathrm{SiO}_{2}$ to form monodisperse 1D nanowires. 


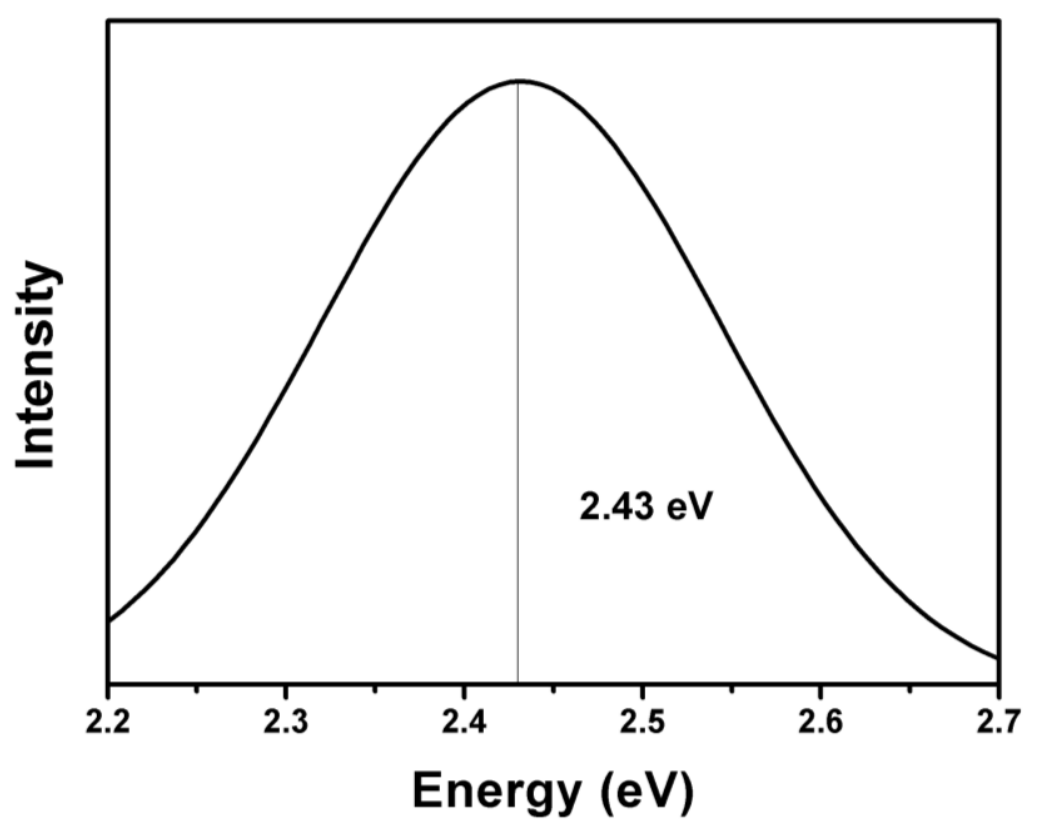

Figure S19. PL data of $1 @$ SBA-15 at $77 \mathrm{~K}$.

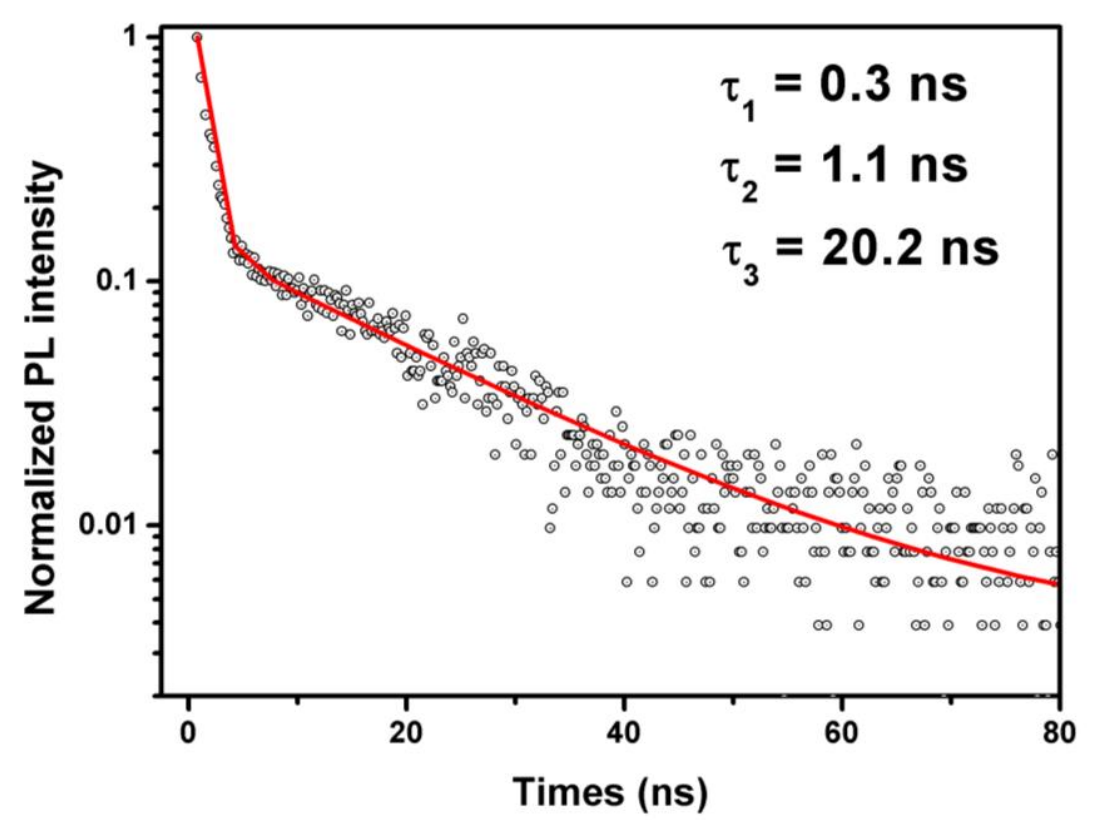

Figure S20. Fluorescence lifetime of $1 @$ SBA-15. This sample have three processes: a short-lifetime process $\left(\tau_{1}=0.3 \mathrm{~ns}\right)$, an intermediate- lifetime process $\left(\tau_{2}=1.1 \mathrm{~ns}\right)$ and a long-lived component $\left(\tau_{3}=20.2 \mathrm{~ns}\right)$. 


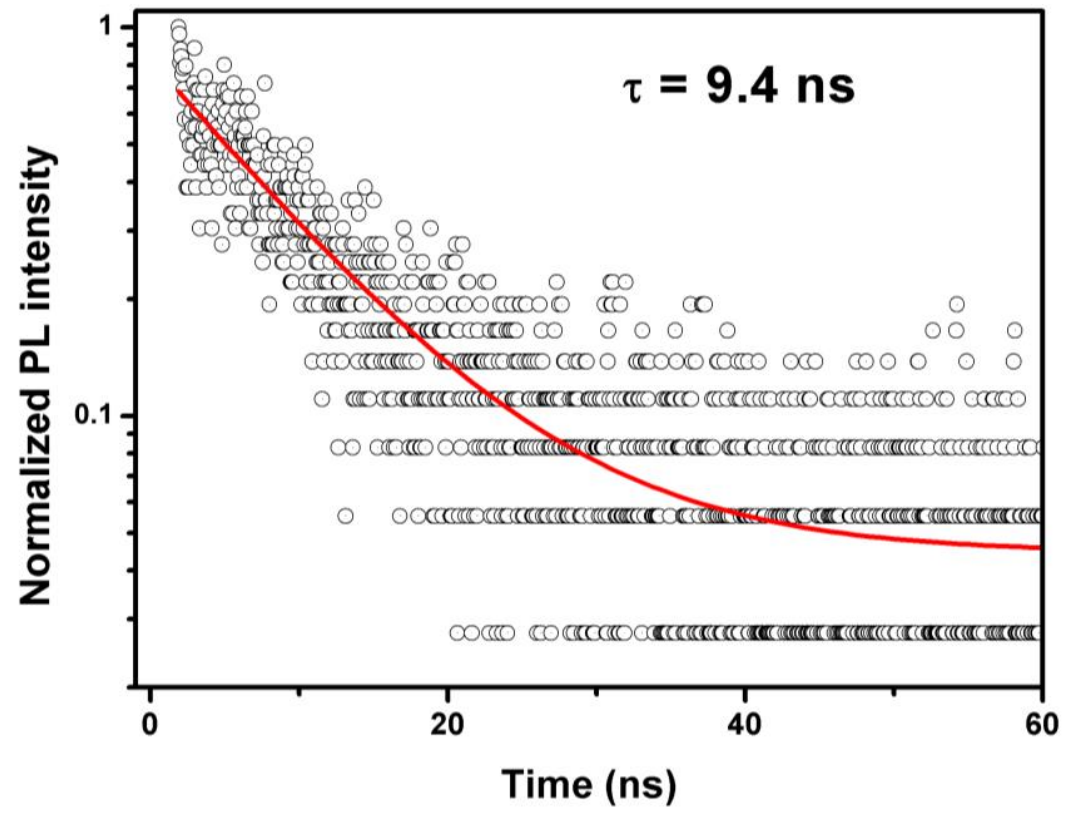

Figure S21. Fluorescence lifetime of $1 @ M C M-41$. This sample only have one processes: a long-lived component $(\tau=9.4 \mathrm{~ns})$. Compared with $1 @$ KIT-6 and $1 @$ SBA-15, the short-life and intermediate-life processes of nanocrystals in $1 @$ MCM-41 have not been observed, which may be due to the size of nanocrystals in $1 @$ MCM-41 is smaller than that of $1 @$ KIT-6 and $1 @$ SBA-15 samples. 